\title{
Atmospheric tides over the Pyrenees: Observational study and numerical simulation
}

\author{
J. Díaz de Argandoña, ${ }^{\text {a* }}$ A. Ezcurra, ${ }^{\mathrm{b}}$ J. Sáenz, ${ }^{\mathrm{b}}$ B. Campistron, ${ }^{\mathrm{c}}$ G. Ibarra-Berastegid ${ }^{\mathrm{d}}$ \\ and F. Saïd ${ }^{\mathrm{C}}$ \\ ${ }^{a}$ Departamento de Física Aplicada I, Universidad del País Vasco/Euskal Herriko Unibertsitatea, Spain \\ ${ }^{\mathrm{b}}$ Departamento de Física Aplicada II, Universidad del País Vasco/Euskal Herriko Unibertsitatea, Spain \\ 'Laboratoire d'Aérologie, UMR 5560 CNRS/UPS, 31400 Toulouse, France \\ ${ }^{\mathrm{d}}$ Departamento de Ingeniería Nuclear y Mecánica de Fluidos, Universidad del País Vasco/Euskal Herriko Unibertsitatea, Spain \\ ${ }^{*}$ Correspondence to: Javier Díaz de Argandoña, Escuela Universitaria de Ingeniería, C/Nieves Cano 12, 01006 Vitoria, \\ Spain. E-mail: javier.argandona@ehu.es
}

\begin{abstract}
Barometric tides around the Pyrenees mountain range are analyzed by means of synoptic surface-station data recorded during one year, surface data from the Pyrenees Experiment (PYREX) and the CRA/LA Very High Frequency (VHF) wind profiler installed in the north of the range. Tides are decomposed into their diurnal and semi-diurnal components. Diurnal tides show a strong non-migrating component and are very dependent on local conditions. Semi-diurnal tides are more homogeneous and present a north-south asymmetry, also noted in the Alps. This cross-range asymmetry could be related to some interference effect caused by the mountain range in the migrating semi-diurnal tide wave. The asymmetry of the diurnal component presents a very strong seasonal variation, probably related to local diabatic effects. A three-month long simulation has been carried out with the National Center for Atmospheric Research's Weather Research and Forecasting (WRF) limited-area model to try to reproduce the tide structure. The validation of the results with wind-profiler data shows reasonable agreement with the observed diurnal tide and poorer results for the semi-diurnal component. At surface level, however, the model reproduces some of the features of the observed semi-diurnal tide, and especially the cross-range asymmetry.
\end{abstract}

1. Introduction

Atmospheric tides (also called atmospheric oscillations) are defined in analogy to oceanic tides as an atmospheric motion of the scale of the Earth, the periods of which are integral fractions of a day and affect pressure and wind. The diurnal, semi-diurnal or terdiurnal variations of pressure are usually masked in the midlatitudes due to the greater variations caused by transient synoptic weather systems (Green, 1970).
The main forcing agent for these oscillations, as opposed to ocean tides, is not the solar or lunar gravity pull but the daily variation in insolation and the thermal effects derived from it. The main components of the solar atmospheric tide are the semi-diurnal, with a 12 hour period, and the diurnal or 24 hour period component. Global-scale tides are usually referred to as migrating tides, and are the result of a gravity wave that travels westwards with the apparent motion of the Sun. Nevertheless, a significant part of the tide can be 
related to local characteristics, and this part is considered as the non-migrating component of the tide (Lindzen, 1979).

Both semi-diurnal and diurnal components have been extensively studied in the last decades. Series of measurements at a great number of stations all around the world have been used to infer global patterns for tides, mainly for migrating tides (Haurwitz and Cowley, 1973; Hamilton, 1980; Dai and Wang, 1999). Also, series of data have been compiled for more restricted areas (Willson, 1975; Mori, 1984; Mass, et al., 1991; Bartzokas, et al., 1995; Riggin, et al., 2002).

According to the classical theory of atmospheric tides (Chapman and Lindzen, 1970), the semi-diurnal tide is mainly forced by heating in the ozone layer due to UV absorption, but also by absorption of infrared radiation by tropospheric water vapour. It presents little zonal variation, so its main component is the migrating tide.

Diabatic heating arising from the absorption of infrared radiation by tropospheric water vapour and from the ground is the main forcing of the diurnal tide. It is strongly influenced by land masses, topography and, in general, the characteristics of the land surface. As a consequence, the diurnal tide is generally much more irregularly distributed than the semi-diurnal one. It presents a more pronounced annual cycle, and is generally greater over land than over sea (Mass, et al., 1991; Bartzokas, et al., 1995; Dai and Wang, 1999).

The classical theory has been complemented by globalscale numerical models that allow us to overcome some limitations of the classical theory, or by the checking of different forcing patterns (Hagan, et al., 1995, 1999; Hagan and Forbes, 2003). These global models do not generally account for small-scale influences on the tides, such as ground topography or small-scale differences in surface sensible heat flux or atmospheric water-vapour content (Kato, 1981).

In a recent work, Hamilton, et al. (2008) carried out a simulation using a general circulation model with a very fine resolution of roughly $10 \mathrm{~km}$ in the horizontal. The authors analyze the influence of topography in the South American Andes region and in the Big Island of Hawaii. Their main finding is a decrease in the semi-diurnal tide amplitude from the eastern to the western side of the mountains, attributed to a shadowing effect of the mountain over the westward-travelling tidal wave.

A different topographic influence was described by Frei and Davies (1993). They observed an asymmetry in the tide amplitude at both sides of the Alps but along the longitudinal direction. By using a simple theoretical model, these authors showed that the mountain could create an interference pattern around the mountain in the migrating tide wave, causing this effect.

It is worth noting that in the above-mentioned simulation from Hamilton, et al. (2008) a similar north-south asymmetry can also be observed in the semi-diurnal tide pattern around Hawaii. From figure 12 of Hamilton, et al. (2008), the latitudinal tidal amplitude gradient far from Hawaii is about $0.05 \mathrm{hPa}$ per degree, while over the island it is $0.1 \mathrm{hPa}$ per degree.

The availability of extensive reanalysis databases has also attracted the interest of researchers wishing to find out about global-scale tide patterns. The usual archived time resolution of these databases is $6 \mathrm{~h}$, the Nyquist frequency for the semi-diurnal tide. Nevertheless, the interpolation method developed by van den Dool, et al. (1997) allows one to extract both diurnal and semi-diurnal tidal signals. Hsu and Hoskins (1989) found good agreement between experimental data and the semi-diurnal tide deduced from a European Centre for Medium-Range Weather Forecasts (ECMWF) analysis. However Ray (2001) and Ray and Ponte (2003) found a bias in the phase of the semi-diurnal tide deduced from GEOS-1, the National Centers for Environmental Prediction/National Center for Atmospheric Research (NCEP/NCAR) reanalysis and the ECMWF operational analysis. In the latter the bias is about $20 \mathrm{~min}$. This systematic error has not been explained yet.

These databases also present the opportunity of making use of them to force a limited-area model in order eventually to obtain a more detailed picture of the tide around topographic features, something not covered by classical theory or coarse-resolution simulations. This is a computationally expensive task, because tide calculation often implies a long integration period. However, due to the limited-area domain, it is much more affordable than simulations using global circulation models of comparable resolution.

The objective of the present work is to analyze the atmospheric tides around the Pyrenees mountain range, to find out whether a pattern similar to that found by Frei and Davies (1993) in the Alps also exists in the Pyrenees and to check whether a limited-area model can reproduce the observed tides.

The next section presents the study area, the data used and the methodology employed for the tide calculation. Section 3 presents the observed tides, their seasonal variation and the characteristics of their amplitudes and phases. Section 4 describes the model simulation performed, the validation of its results against Very High Frequency (VHF) windprofiler data and the tides found from the simulation. The final section summarizes the main findings.

\section{Study area, data and methodology.}

The Pyrenees is a simple mountain range of elliptic shape lying on the Spanish-French border with its main axis in the zonal direction. Its length is about $400 \mathrm{~km}$ and its width $80 \mathrm{~km}$ in its central part, with a maximum height of about $3000 \mathrm{~m}$ in the same area. In the south of the Pyrenees, the Iberian range delimits the Ebro Valley, an almost flat river valley with a triangular shape. In the north of the Pyrenees the terrain is generally flat, except for the Massif Central in the northeast of the Pyrenees.

Regular pressure data from several synoptic stations around the mountain have been recorded from the internet server of the the Department of Atmospheric Science of Wyoming University (http://weather.uwyo.edu) every day during 2007. There are no regular meteorological stations inside the mountain range. For this reason we have also used some data from the Pyrenees Experiment (PYREX: Bougeault, et al., 1990). The PYREX measurements were collected during 1990 and include surface measurements in locations not available in the synoptic network, inside the mountain range. From the PYREX experiment data, only the specially devised microbarograph transect, designed to compute the mountain drag, has been used in this study (Bessemoulin, et al., 1993). Additionally, a three-month data record from the VHF wind profiler, installed at Lannemezan in the north-central part of the mountain chain, has also 
been used to assess the vertical structure of the tide and to validate the model results. In Table I we summarize the data used. Figure 1 shows the geographical domain and the location of the stations used in this work, together with the $1000 \mathrm{~m}$ height contour.

We have used the standard method to obtain the diurnal and semi-diurnal components of surface barometric tides. It consists of averaging the hourly pressure values during a given time span, creating a sort of composite day. The difference between each hourly average pressure and the total average gives the mean pressure perturbation at each hour of the day during the period considered. No reduction to sea level has been made. This calculation is frequently made using periods of time such as one month, three months or one year (Chapman and Lindzen, 1970). We have chosen a three-month period for the synoptic and profiler data and the whole PYREX observational period (two months).

Once we have obtained the diurnal pressure perturbation cycle, the diurnal and semi-diurnal components are worked out by Fourier fitting of the signal. The resulting components are characterized by their amplitude and phase, using

$$
\Delta p=S_{1} \sin \left(t+\phi_{1}\right)+S_{2} \sin \left(2 t+\phi_{2}\right),
$$

Table I. Databases used in this study and their main characteristics.

\begin{tabular}{lclc}
\hline & No. of stations & Period & Resolution \\
\hline Synoptic & 7 & 1 year (2007) & $1 \mathrm{~h}$ \\
PYREX & 15 & Oct-Nov 1990 & $10 \mathrm{~min}$ \\
L. Profiler & 1 & Jun-Aug 2002 & $15 \mathrm{~min}$ \\
\hline
\end{tabular}

where $t$ is the local mean solar time expressed in radians for the station referred to, $S_{1}$ and $S_{2}$ are the diurnal and semidiurnal solar tide amplitudes and $\phi_{1}$ and $\phi_{2}$ the phases. The residuals from this fitting are in general very small, as diurnal and semi-diurnal harmonics are the prevalent modes. An example is presented in Figure 2, where the fit and spectrum of the different harmonics are plotted.

The errors of both amplitudes and phases have been estimated using the method proposed by Bartels (1927) and outlined by Chapman and Lindzen (1970). This procedure is based on using several data sets to calculate different tidal parameters in the same location. The distribution of these parameters is then used to obtain the tide mean values and their uncertainty. We have obtained different data sets by randomly generating subsets of the available days for each period, e.g. randomly choosing 45 days from the 90 days in each of the three-month periods. From each subset, the tidal parameters have been calculated and the dispersion of these values has been used to estimate the error. We have tried different sizes for the subsets, and we can conclude that if the size of the sample is large enough (about 15 days) then the uncertainty obtained is virtually independent of the sample size.

After characterizing the tide using these experimental data, a three-month long integration has been carried out using NCAR's Weather Research and Forecasting (WRF) limited-area model. A first validation of the model wind results for the whole integration time has been made by comparing them with the wind observed by the profiler. We have used the correlation coefficient, the slope of the fitting line and the normalized root-mean-square (r.m.s.) error.

Next we have checked the ability of the model to reproduce the wind tide. A direct comparison of the local amplitudes and phases of the diurnal and semi-diurnal tides of the two components of the wind at different levels can obviously

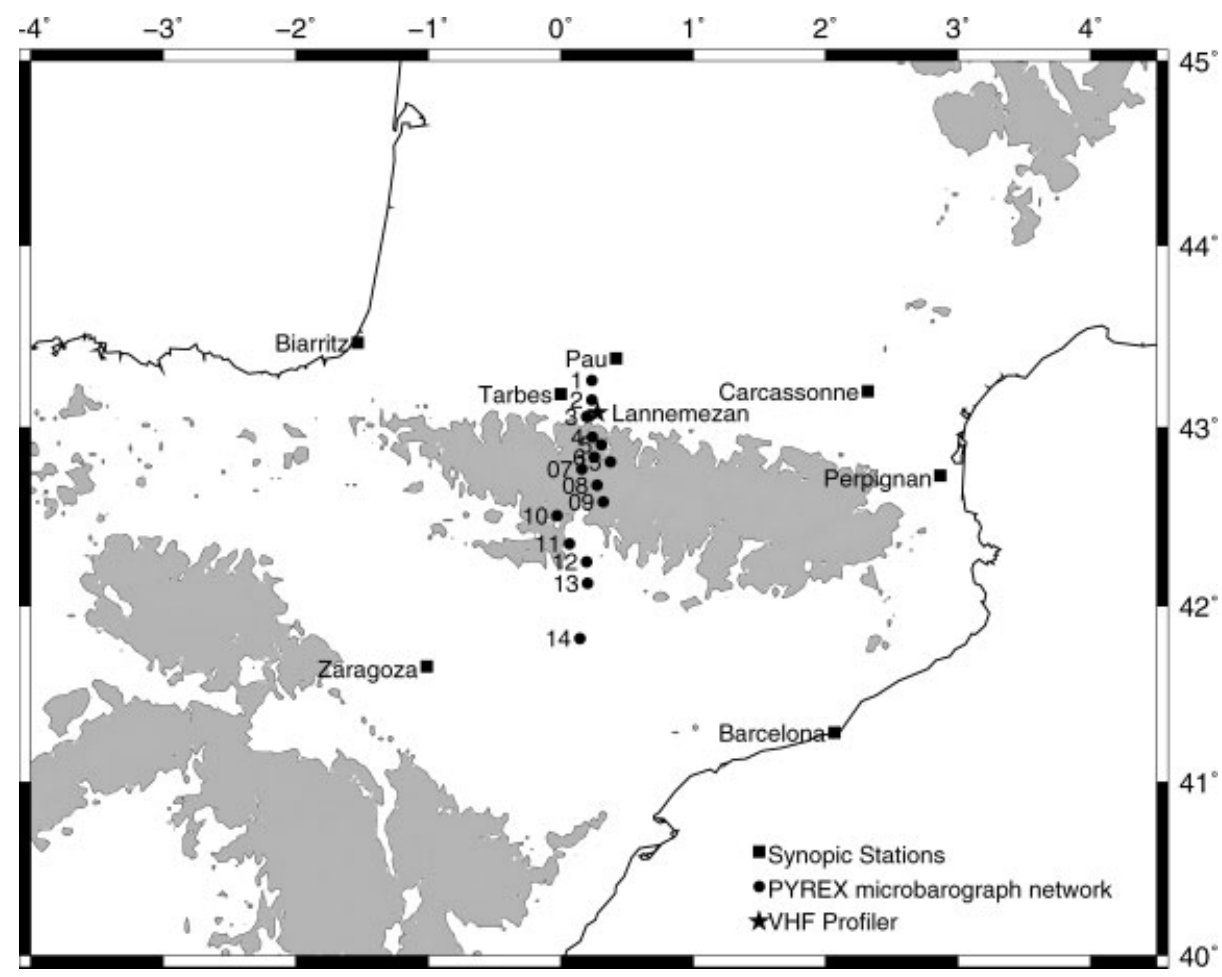

Figure 1. Geographical domain and location of the stations used in this study. Regular synoptic stations are marked with a square, the microbarograph network from PYREX with circles. The CRA/LA VHF wind-profiler situation is indicated with a star. The shadowed regions correspond to terrain higher than $1000 \mathrm{~m}$. 

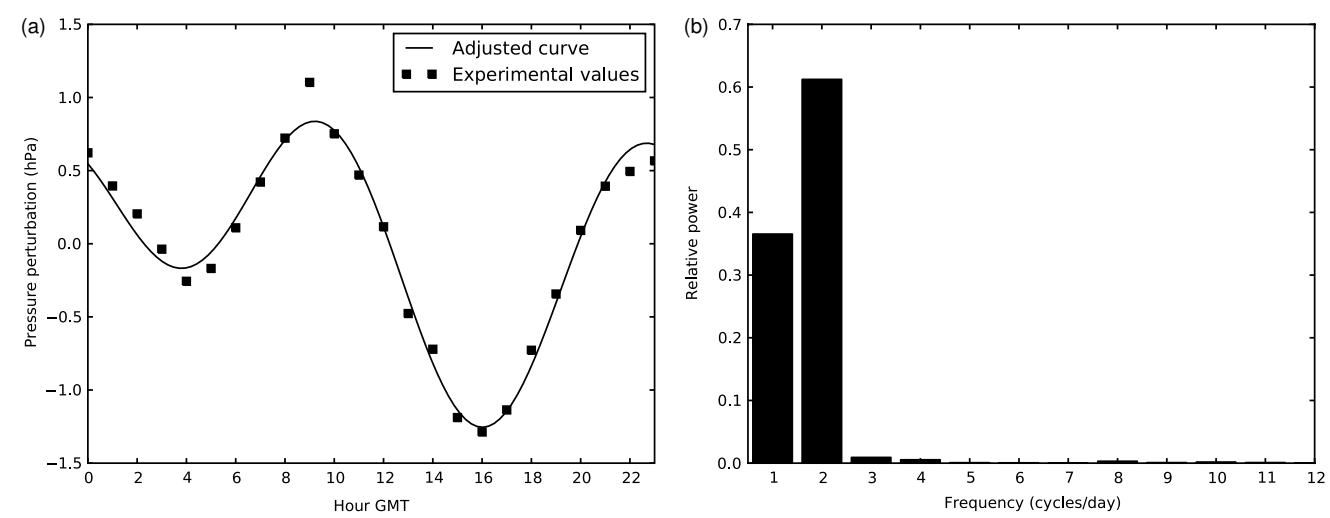

Figure 2. (a) An example of the fit obtained using the leading two harmonics (24 and $12 \mathrm{~h}$ ) against the observed diurnal cycle. (b) Power spectrum of the harmonic analysis, showing the prevalence of the first two components. This example corresponds to the February-April period in Zaragoza.
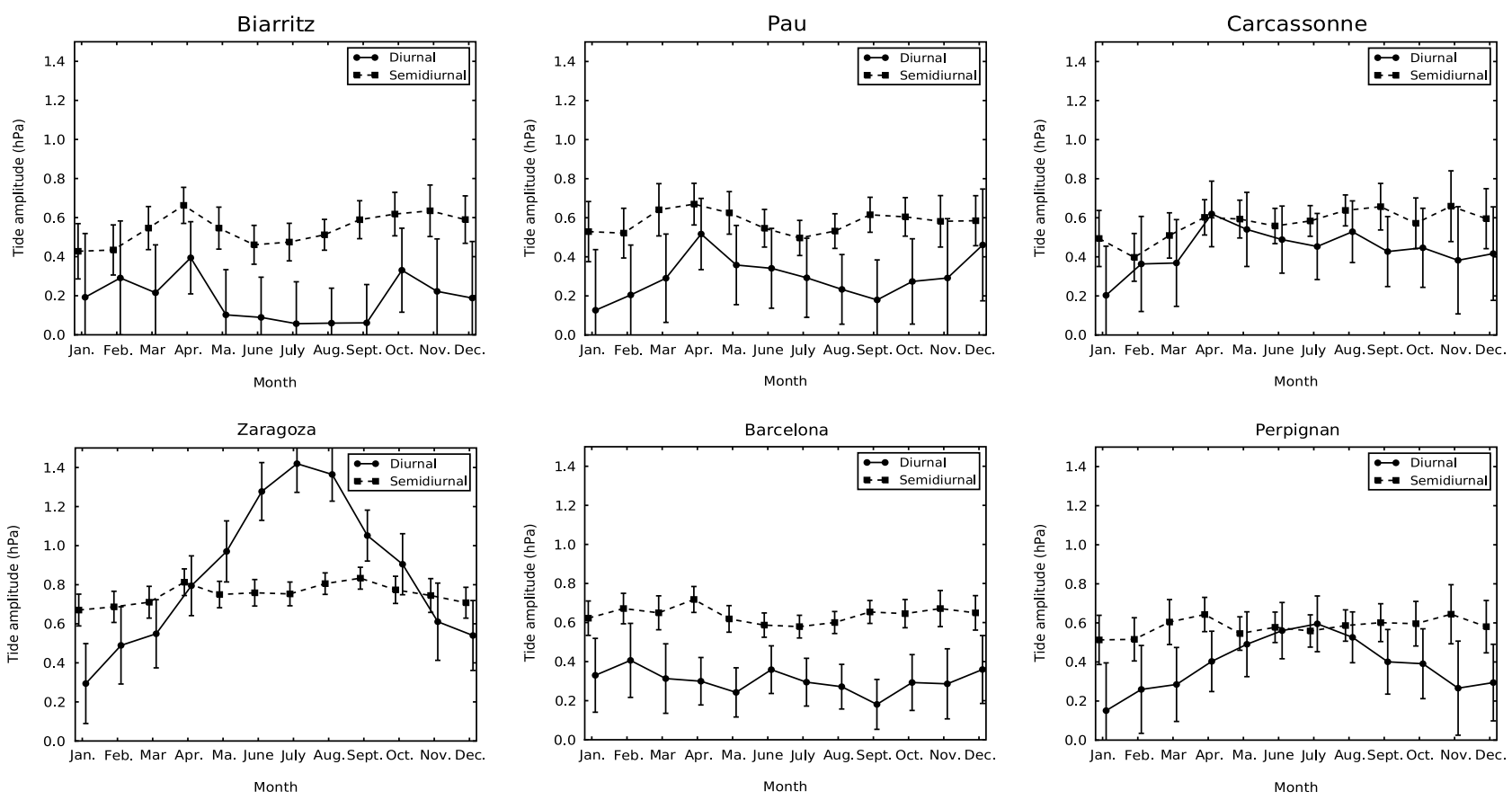

Figure 3. Seasonal variation of the diurnal and semi-diurnal tidal amplitude for synoptic stations. The error bars represent the probable error of the amplitudes, see text for details.

be made. Instead of using that procedure, we have first compared the cycles of the observed and modelled wind and then the diurnal and semi-diurnal components. This method allows us to obtain a better picture of the vertical diurnal cycle structure as a whole.

Finally, we have compared the observed and modelled semi-diurnal tides for the ground stations. It must be pointed out, however, that the observation and model periods come from different years. Hence we have only compared the semidiurnal tide, because it generally shows little interannual variability (Cooper, 1982; Bartzokas, et al., 1995)

\section{Experimental results}

\subsection{Seasonal and spatial variation in tides}

We have used three-month periods, centred on the reference month (e.g. June values correspond to the May, June and July period), to obtain the seasonal variation of the tides from the 2007 regular synoptic-station data. Figures 3 and 4 show the amplitudes and phases of the resulting tides throughout the year. Following the criterion proposed by Cooper (1984), some station data have been rejected, and Tarbes is not shown for compactness. The mean and standard deviation for the diurnal and semi-diurnal tidal amplitudes and phases for each station along the year are summarized in Table II.

For nearly all the stations, the semi-diurnal component is predominant over the diurnal one. A notable exception is the station of Zaragoza, for which the diurnal component in summer is double the semi-diurnal amplitude. In general the semi-diurnal component is much more uniform both through the year and between stations than the diurnal one.

The error bars in Figures 3 and 4 must be interpreted with care when the errors in amplitude are greater than the mean values (e.g. in some diurnal components, especially in Biarritz). Notice that the errors are calculated from the distribution of the tidal vectors (amplitude and phase) and not separately from the amplitude and phase distributions. When the amplitude error is larger than the amplitude mean value, it does not of course mean that the amplitude could reach negative values, but usually reflects a large variability in the phases of the samples. As a consequence, when the 

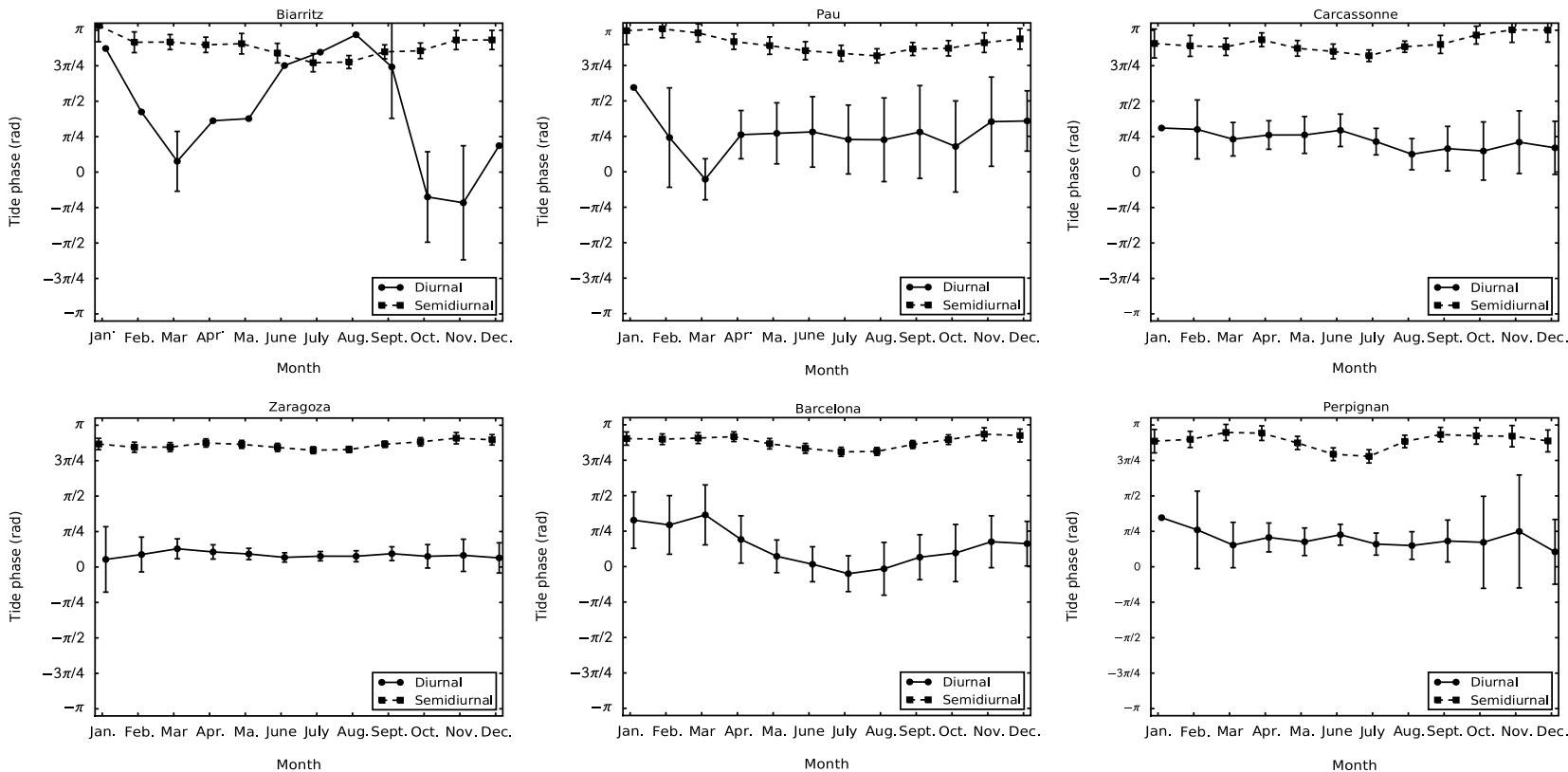

Figure 4. Seasonal variation of the diurnal and semi-diurnal tidal phase for synoptic stations. The error bars are only drawn if the tidal amplitude is greater than its uncertainty.

Table II. Values of the mean and standard deviation (in brackets) of seasonal amplitude and phase distributions of the tides for each of the synoptic stations.

\begin{tabular}{lcccc}
\hline \multirow{2}{*}{ Site } & \multicolumn{2}{c}{ Diurnal } & \multicolumn{2}{c}{ Semi-diurnal } \\
\cline { 2 - 3 } & $S_{1}(\mathrm{hPa})$ & $\phi_{1}(\mathrm{rad})$ & $S_{2}(\mathrm{hPa})$ & $\phi_{2}(\mathrm{rad})$ \\
\hline Biarritz & $0.18(0.1)$ & $1.5(1.3)$ & $0.54(0.08)$ & $2.8(0.2)$ \\
Tarbes & $0.19(0.1)$ & $1.2(0.8)$ & $0.55(0.07)$ & $2.7(0.08)$ \\
Pau & $0.30(0.1)$ & $0.8(0.5)$ & $0.58(0.05)$ & $2.9(0.2)$ \\
Carcassonne & $0.44(0.1)$ & $0.7(0.2)$ & $0.57(0.08)$ & $2.9(0.2)$ \\
Perpignan & $0.39(0.1)$ & $0.6(0.2)$ & $0.58(0.04)$ & $2.8(0.2)$ \\
Barcelona & $0.30(0.1)$ & $0.4(0.4)$ & $0.64(0.04)$ & $2.8(0.1)$ \\
Zaragoza & $0.86(0.4)$ & $0.3(0.1)$ & $0.75(0.05)$ & $2.7(0.08)$ \\
\hline
\end{tabular}

error amplitude is greater than its mean value we have an almost complete indeterminacy in the phase. In these cases, no phase error bars have been drawn in Figures 3 and 4. In spite of the large error bars, the calculated amplitude can be significant in some cases, in the sense that the dispersion of the amplitude values will be in general much smaller than that indicated by the error bar, and the mean of the amplitudes much larger than the amplitude of the mean vector. In Figure 5 the samples from three stations have been represented for the June-July-August (JJA) period. It can be observed that the lower amplitude in Biarritz is mainly a consequence of the dispersion in the phase values.

\subsubsection{Diurnal tide}

The amplitude of the diurnal component shows some seasonal variation for all stations (Figure 3). Related to this fact, the uncertainties are in general quite large, indicating that the diurnal tide is far from being a constant phenomenon but can present a very large variation from month to month.

The patterns in Zaragoza and Perpignan are similar, with a maximum in summer and a minimum in winter. This variation is especially intense in Zaragoza, for which the amplitude in summer is just four times the amplitude in winter. In Perpignan the variation is much less pronounced but nevertheless significant.

In contrast Biarritz, a coastal station, shows a completely different cycle, with a nearly zero diurnal tide from May-September and two maxima in April and October. Seasonal cycles in Pau and Tarbes (the latter not shown) are similar to Biarritz's, with larger summer amplitudes. Carcassonne shows a minimum in winter, and the diurnal tide in Barcelona varies from $0.2-0.4 \mathrm{hPa}$ with minima in spring and autumn.

The diurnal tide amplitude is generally greater in continental stations than in some coastal ones (Barcelona and Biarritz), as shown by Dai and Wang (1999). The increase in the thermal inertia caused by the vicinity of the ocean is probably the cause of this weakening of the tide amplitude. The sea-breeze circulation, closely related to this effect, will also attenuate the pressure signal compared with a continental station. Perpignan, however, shows a bigger diurnal tide amplitude in summer than the French continental stations.

As mentioned above, Figure 5 shows that the low values of the summer diurnal amplitudes in Biarritz are related to the dispersion of the phases rather than to a weakening of 


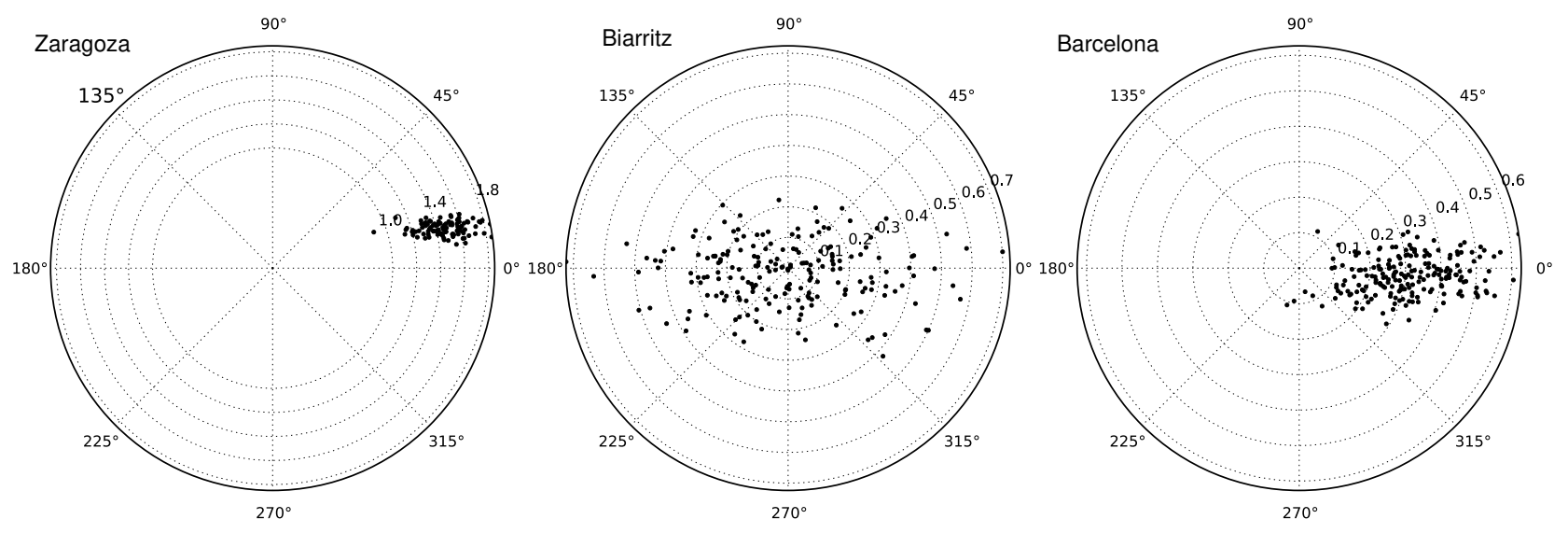

Figure 5. Distribution of the diurnal tides obtained from 100 (Zaragoza and Barcelona) and 200 (Biarritz) random samples of 45 day size for the JJA period. The tide amplitude calculated for each sample is represented by the distance from each point to the origin and the phase by the angle from the horizontal counterclockwise. Notice that the great variability in the phase of the diurnal tide in Biarritz will lead to a very weak mean amplitude. Observe also the different patterns in the two coastal stations, Barcelona and Biarritz. The units of the label values are hPa.

the pressure variation amplitude. In this figure it can be seen that the amplitudes are comparable to those in Barcelona but the phases are mainly grouped around $0^{\circ}$ and $180^{\circ}$. The scattering of the phases shows that the diurnal variation of pressure in Biarritz is not a well-organized phenomenon in the sense that although some diurnal oscillation exists it does not follow the same pattern from day to day. This diurnal oscillation cannot be considered as a proper diurnal tide, because it is not a periodical, repetitive oscillation. In contrast, the amplitude of the pressure cycle in Barcelona shows some variation, but the phase is nearly constant (i.e. the points in Figure 5 are grouped around the $0^{\circ}$ phase line). This feature suggests that the diurnal pressure oscillation in Barcelona is mainly driven by the diurnal heating cycle, developing a diurnal tide as in a continental station but not in Biarritz.

This could be, at least partially, explained by the different topography of the two sites. The terrain is hilly in the surroundings of Barcelona, and this could contribute to the strengthening of the sensible heat flux diurnal cycle. In Biarritz, however, the terrain is quite flat, so the stable marine layer could more easily prevent the development of a heating-related diurnal pressure cycle. The analysis of the numerical simulation carried out for the summer period (see section 4) shows a well-developed sea breeze in Barcelona and a very weak one in Biarritz, sustaining this hypothesis. The difference in the climatology of the two stations, with Biarritz more exposed to synoptic perturbations from the Atlantic, could also contribute to the difference.

In general both the values and the seasonal pattern of the diurnal tide are very dependent on location. The large diurnal tide amplitude in Zaragoza, the most continental station, together with its great seasonal variability and summer maximum, very likely reflects the influence of the ground sensible heat flux in the non-migrating tide (Dai and Wang, 1999; Mass, et al., 1991), probably enlarged by the thermal effect of the valley.

Díaz de Argandoña, et al. (2003) showed that the mean topography-induced pressure perturbation at the south of the Pyrenees reaches maximum values of $7 \mathrm{hPa}$ in Zaragoza, and, as shown above, the diurnal modulation in the pressure in Zaragoza could be as great as $1.4 \mathrm{hPa}$. The orographic pressure dipole is closely related to the wind circulations around the Pyrenees (Bènech, et al., 1998), so there must be a significant diurnal modulation in the momentum budget and the associated circulations around the Pyrenees.

All these features indicate that the diurnal tide in the surroundings of the Pyrenees is strongly influenced by the local conditions of the stations, so we can conclude that the main part of this tide is of non-migrating nature. The phase shift noted some days in Biarritz in summer with a reversal cycle has to be explained, however.

\subsubsection{Semi-diurnal tide}

The semi-diurnal component also presents an annual modulation, but the amplitude of this variation is much less important than the amplitude of the diurnal tide (Figures 3 and 4). The errors are also much smaller than in the diurnal tides, and no significant dispersion in phase, similar to that in the Biarritz diurnal tide, can be found. The annual pattern is very similar in all the stations, with two maxima in spring and autumn and two minima in late winter and summer (Figure 3). The amplitude also presents a much weaker variability between stations than the diurnal component.

The phase of the semi-diurnal component is more or less constant through the year and from one station to another, as can be seen in Table II and in Figure 4, although again some modulation does exist. The mean value of the phase of the semi-diurnal component for all stations coincides fairly well with the $159^{\circ}$ value proposed by Haurwitz and Cowley (1973).

The features of the semi-diurnal component, such as its homogeneous values, its almost identical cycle in all the stations and its lower error, all indicate that this component is not much dependent on local conditions. Its origin must therefore be mainly the migrating tide. Nevertheless the coastal stations present a somehow weaker semi-diurnal signal than the continental stations at comparable latitude (e.g. Biarritz versus Pau or Barcelona versus Zaragoza). This difference is about $0.04 \mathrm{hPa}$ in the north and $0.1 \mathrm{hPa}$ in the south.

\subsection{Asymmetry of the tide around the mountain range}

In a study carried out around the Alps, Frei and Davies (1993) found that the tide amplitudes were greater in the south of the Alps than in the north. The asymmetry was present in 
both tide components, but the cited authors emphasized the diurnal one. From a simulation by Hamilton, et al. (2008), a similar phenomenon seems also to be present in Hawaii.

This asymmetry can also be found in our data, as seen in Table II. Nevertheless this conclusion is supported only by data from two stations in the south, so it must be made with care. The mean values of the semi-diurnal tide amplitude for stations in the south of the Pyrenees (Barcelona and Zaragoza) are systematically greater than the corresponding values in the north, especially if we compare the coastal stations (Barcelona versus Biarritz) and the continental stations (Zaragoza versus others).

The asymmetry is not so clear in the diurnal amplitude and there is a key difference: the diurnal amplitude asymmetry is heavily seasonally dependent. For example, between Zaragoza and Biarritz the difference is about $0.05 \mathrm{hPa}$ in January and nearly $1.4 \mathrm{hPa}$ in July. This annual variation is not observed in the semi-diurnal amplitude meridional gradient and did not appear in the Alps (Frei and Davies, 1993), although in this case all the stations are continental.

In the empirical distributions proposed for barometric tides (Haurwitz and Cowley, 1973; Hamilton, 1980; Dai and Wang, 1999), the global distribution of the tide amplitude depends on the latitude. This variation can only account for $0.02 \mathrm{hPa}$ and $0.04 \mathrm{hPa}$ for the diurnal and semi-diurnal tide amplitudes in our case. This is clearly not enough to explain the asymmetry observed (nearly $0.2 \mathrm{hPa}$ between Zaragoza and continental north stations, and $0.1 \mathrm{hPa}$ between the two coastal stations for semi-diurnal tides).

No significant shadowing effect can be found between Perpignan and Biarritz in the semi-diurnal tide, but this is probably due to the geometry of the Pyrenees, lying in the zonal direction.

It has not been possible to obtain reliable diurnal tides from the PYREX data, because of the great dispersion of the tidal parameters and their very large errors. Related to this fact, and in contrast to the data from the synoptic stations, the tide spectra show that some of the higher order harmonics are larger than the diurnal one. We can conclude that the two-month time span is probably not long enough to obtain a significant diurnal signal from the data. A check performed in the three-month data recorded from the wind CRA/LA VHF profiler, also used in this study, results in a similar conclusion.

Figure 6 shows the semi-diurnal tidal amplitudes and phases along the PYREX microbarograph transect, obtained from the whole observational period (October and November 1990). The amplitudes are clearly greater in the south than in the north of the mountain range and this supports the presence of an asymmetry along the range.

The amplitude of the semi-diurnal tide presents a marked reduction with height, of about $0.35 \mathrm{hPa}$ over $2000 \mathrm{~m}$. A similar reduction of the semi-diurnal tide amplitude with height has been documented in several studies (e.g. Chen, et al., 2001; Hamilton, et al., 2008) and it is compatible with the classical theory of the semi-diurnal tide.

The tide asymmetry found implies that both the drag and the topographic pressure dipole must present a daily variation. Sure enough, both the drag calculated during the PYREX experiment and the pressure dipole intensity during the same period show tidal cycles. The tidal results for these two parameters are shown in Table III. Again we find that the diurnal and semi-diurnal modulation in drag, of the order of $0.2 \mathrm{~Pa}$, is significant, as the mean absolute
Table III. Amplitude and phase of the diurnal and semidiurnal tides of the drag measured during PYREX and the pressure difference across the Pyrenees.

\begin{tabular}{lcclcc}
\hline & \multicolumn{2}{c}{ Diurnal } & & \multicolumn{2}{c}{ Semi-diurnal } \\
\cline { 2 - 3 } & $S_{1}(\mathrm{~Pa})$ & $\phi_{1}(\mathrm{rad})$ & & $S_{2}(\mathrm{~Pa})$ & $\phi_{2}(\mathrm{rad})$ \\
\hline Drag & 0.1380 & -2.358 & & 0.1914 & -0.508 \\
$\Delta p$ & 65.08 & -2.931 & & 24.18 & -0.925 \\
\hline
\end{tabular}

value measured during PYREX was $2.2 \mathrm{~Pa}$ with a standard deviation of 1.7 Pa. Unfortunately, the data from the PYREX experiment do not allow us to extend the analysis to the seasonal cycle of a whole year.

Several physical processes have been proposed by Frei and Davies (1993) to explain the origin of the asymmetry in the diurnal tide over the Alps. The first group, comprising processes such as differential solar heating by albedo variations or slope exposition, is related to the spatial variation of the local thermal forcing. Although this group could produce some effect on the diurnal tides, it is improbable that the semi-diurnal tide is significantly affected by this kind of local effect (Chapman and Lindzen, 1970).

The dynamic effect of the mountain on the incident air flow is very dependent on the conditions of the incident air mass. Some of these conditions, in particular the vertical stratification, could probably present a systematic day-night variation and thus produce a variation in the diurnal cycle of the pressure difference across the ridge. Hence the sign of this variation would depend on the direction of the incident air stream, and so on the sign of the drag. We have compared the tidal amplitudes and phases with the mean value of the drag over a number of samples and found no correlation.

A simple theoretical model used by Frei and Davies (1993) predicts the existence of a mesoscale trapped Kelvin wave that interferes destructively (constructively) with the tidal migrating wave to the north (south) of the mountain range. The result of this interference will be the observed asymmetry in the tidal amplitude.

In the case of the Pyrenees, the seasonal variation of the diurnal tide is very irregularly distributed between the stations (compare Biarritz with Zaragoza, for example) and this irregularity leads to a strong seasonal variation in the asymmetry, hard to explain with only an interaction of a planet-scale wave with the topography. Hence, we do not think this explanation alone could be applied to our domain. The seasonal variation of the asymmetry is also compatible with a difference in the ground thermal balance. In our case the surface heat flux is added to the interference mechanism by the above-cited authors.

On the other hand, the annual cycle of the semidiurnal tide shows a similar pattern for all the stations, which strongly suggests a common origin for all these perturbations. From this point of view, an explanation similar to that proposed by Frei and Davies (1993) for the diurnal tide seems admissible for the spatial structure of the semi-diurnal tide observed in the present study.

\section{Numerical simulation}

In the previous section, we have shown that the barometric tides around the Pyrenees are far from homogeneous. It is very likely that the topography and the soil type play an 

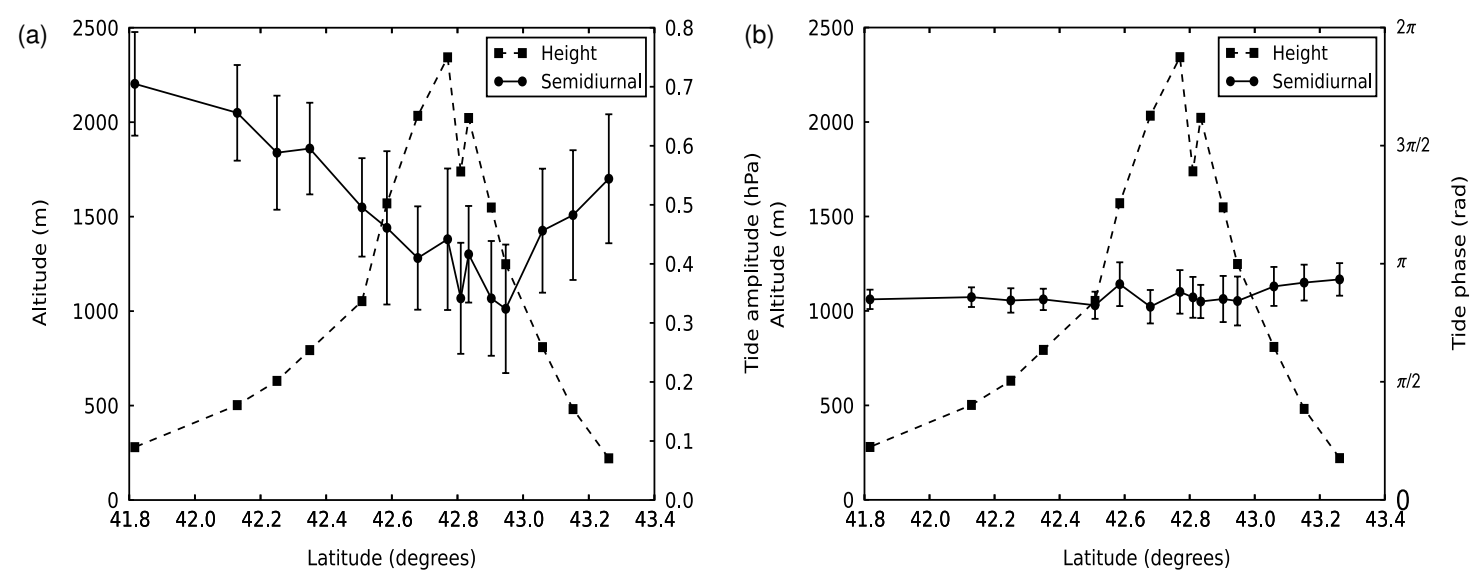

Figure 6. (a) Amplitude and (b) phase for semi-diurnal tides along the PYREX transect. The terrain height has also been represented.

important role in the tide distribution, by interfering with the migrating tidal wave, by altering the thermal budget near the ground or by additional effects such as the influence of the topography on the distribution of vertically integrated water content (e.g. Smith, 1979), which will impact diabatic heating by infrared radiation. In order to depict the main features of the tidal distribution, we have used NCAR's WRF limited-area model, forced by ECMWF's ERA40 reanalysis data. We have chosen the period from June-August 2002, as this is the period of the available CRA/LA VHF windprofiler data, so we can use it to validate the model results. Additionally, it corresponds to the season of the year that shows the most intense spatial variation in the diurnal tide.

\subsection{Model setup}

Integration by means of the non-hydrostatic WRF version 2.2.1 mesoscale model has been arranged as follows. There exist two domains: the larger one (D1) has a horizontal resolution of $75 \mathrm{~km}$, whilst the smaller one (D2) has a grid size of $15 \mathrm{~km}$. The results of D2 have been analyzed in subsequent sections of this article, after discarding a five-point strip at the borders. The nesting between both domains is two-way. The boundary conditions are updated every $6 \mathrm{~h}$ from the ERA40 reanalysis data at a horizontal $1.125^{\circ}$ grid resolution. The WRF model has 35 vertical $\eta$ levels reaching $20 \mathrm{hPa}$ in the top layer. Vertical interpolation is linear in logarithm of pressure and the time step in the largest domain is $300 \mathrm{~s}$. The microphysics parametrization used is the WRF Single Moment 3-class simple ice scheme (Hong, et al., 2004). Radiation is computed according to the CAM scheme, both for long- and short-wave radiation, updating radiation computations every $10 \mathrm{~min}$. The landsurface model consists of a thermally diffusive five-layer soil with a surface-layer scheme given by MM5 Monin-Obukhov similarity theory and a YSU planetary boundary-layer (PBL) parametrization scheme. The cumulus parametrization scheme used is the Betts-Miller-Janjic one (Skamarock, et al., 2007).

Some of the tidal signals already present in the reanalysis will be forced to the model by the boundary conditions. As the six-hour frequency is just the Nyquist frequency for the semi-diurnal tide, the intensity of this forcing will depend on the exact location of the external domain borders. In our case, only about $10 \%$ of the reanalysis semi-diurnal signal will be forced to the model, so virtually all the semi-diurnal tides present in the results will be produced by the WRF model itself.

\subsection{Validation of the model results}

Model wind results from the simulation are compared with the observed wind measured at three different levels in Figure 7. The model seems to capture well the main tendency of the observed wind, especially in the intermediate $6000 \mathrm{~m}$ level. To assess the accuracy of the model representation, we have calculated the correlation coefficient, the slope of the fitting line and the normalized r.m.s. error between the observed and modelled wind velocities at 37 vertical levels. The results for the different levels and wind components are shown in Figure 8. The best general agreement is observed between 4000 and $14000 \mathrm{~m}$, simultaneously indicated by the three parameters considered. In this region the r.m.s. error, normalized against the mean value of each component intensity, takes a value of 0.4 for the zonal component and 0.7 for the meridional component. The linear regression slope, of the order of 0.9 in both cases, shows that the model generally underestimates the observed wind.

In the lower levels the inaccuracy of the model output could be related to the strongly smoothed-down topography used by the model or a deficient representation of the PBL processes. The poor agreement above $14000 \mathrm{~m}$ can be explained by the progressively weaker signal-to-noise ratio of the profiler above $12000 \mathrm{~m}$, so the measurement above this level could be of insufficient quality.

We can conclude that the model simulation reproduces the profile of the observed wind at Lannemezan with reasonable accuracy, in a layer between 4000 and $14000 \mathrm{~m}$. Below this layer the results are progressively worse. Aloft the results are uncertain, as the measured wind is probably not of high quality.

\subsection{Model and observed wind tides}

Both diurnal and semi-diurnal tidal signals are clearly present in the observed wind profile and the model results.

Using a technique similar to that used in the analysis of data from the surface, the hourly diurnal variation of the wind has been obtained for both the model and the VHF profiler data. Also, the diurnal variation due to either diurnal or semi-diurnal components and the sum of the two 

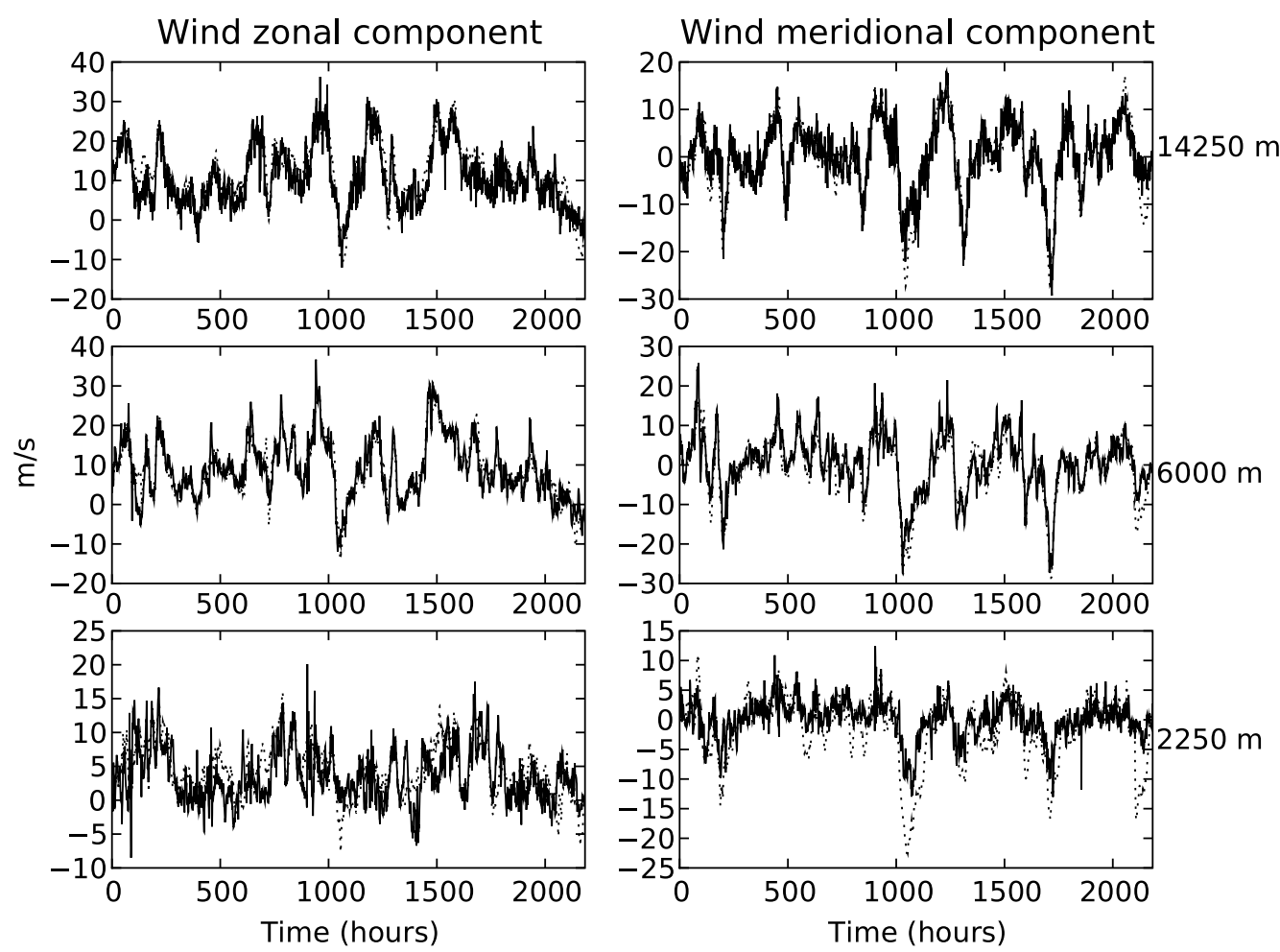

Figure 7. Comparison of the measured wind component with the modelled wind at three different levels for the Lannemezan station. The continuous line represents the measured wind and the dotted line the model output.
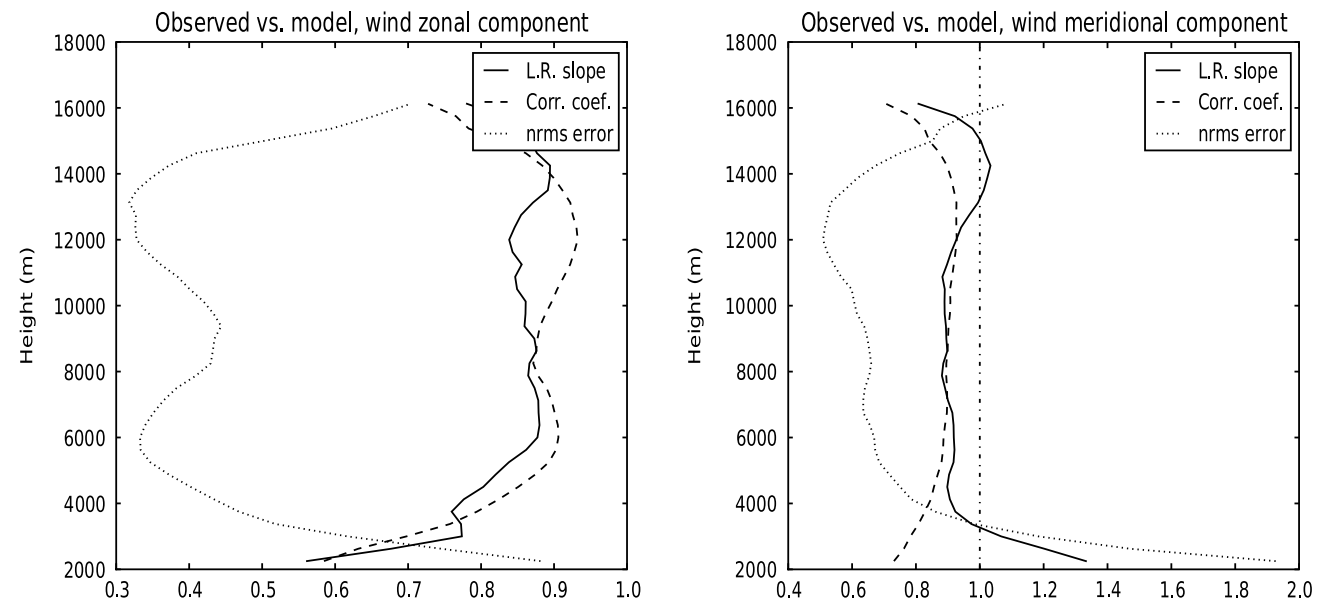

Figure 8. Comparison between observed and modelled wind components at different levels for the Lannemezan station. The curves show the slope of the linear fit, the correlation coefficient and the normalized r.m.s. error.

has been computed. Finally, as a quality check of the tidal model results, the difference between all these values has been obtained. The results are shown in Figure 9 (we will refer to the panels in this figure as $(i, j)$, meaning the $i$ th row and $j$ th column).

The main feature of the observed diurnal cycle is a strong modulation in the meridional component of the wind, with maxima at $4 \mathrm{~h}$ (southwards) and $14 \mathrm{~h}$ (northwards). There is also a southwestward anomaly between 5000 and $10000 \mathrm{~m}$ at about $21 \mathrm{~h}$. The first two features are qualitatively well represented in the model cycle (Figure 9(2,1)), although the first appears earlier (at $2 \mathrm{~h}$ ) and the second shows a discontinuity below $6000 \mathrm{~m}$, not observed by the profiler. The last feature is also reproduced, but at a lower level $(4000 \mathrm{~m})$. These differences can also be observed in Figure $9(3,1)$, from which we can conclude that the diurnal cycle is reasonably well represented above $5000-6000 \mathrm{~m}$ but not below that level.

Comparing the diurnal component of the tide (Figure 9, column 2) we again find generally good agreement above $5000 \mathrm{~m}$, with poor results below this level.

The semi-diurnal component is weaker than the diurnal in both observed and modelled data. The patterns are different in both, and the modelled tides are generally much weaker than the observed ones. In particular, the strong modulation in the wind direction at $4000-8000 \mathrm{~m}$ is not present in the simulation. The strongest amplitudes in the simulated tide appear in two layers, one below $5000 \mathrm{~m}$ and the other at $9000 \mathrm{~m}$. The lower layer presents a variation of the meridional component, and the other of the zonal component.

Taking into account the comparisons carried out, the wind tides obtained from the model are far from perfect, 

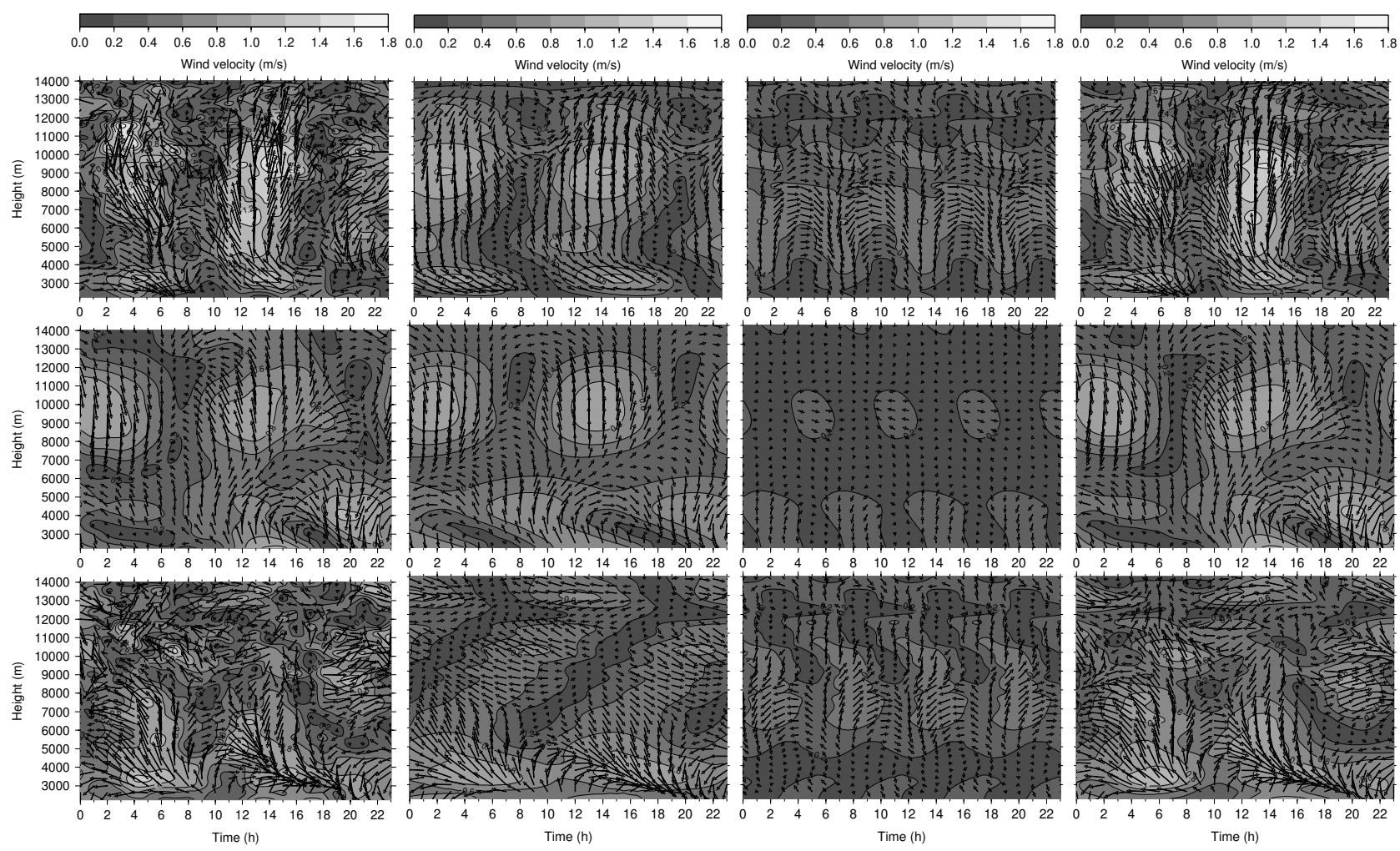

Figure 9. Perturbation of the wind velocity as a function of time and height. The first row represents measured data, the second row modelled data and the third row the difference between them. The first column represents the raw perturbation of the wind, the second column the diurnal component, the third column the semi-diurnal component and the last column the sum of both diurnal and semi-diurnal components. The vectors represent the direction of the horizontal wind perturbation (north upwards, west leftwards).

especially for the semi-diurnal component. Nevertheless, some features of the tides are reasonably reproduced, especially considering that the diurnal component is predominant during the summer. As the tidal signal in the ground pressure can be considered as a consequence of the vertically integrated atmospheric variation, we can expect a reasonable representation of the barometric tides at ground level by the model.

\subsection{Surface-pressure tides}

The ground-pressure field obtained from the numerical simulation clearly presents diurnal and semi-diurnal tides, again with a negligible residual. In Figure 10, the amplitude and phase of both tides are represented for grid model points using a vector convention: the amplitude is represented by the vector's length and the phase by the direction of the vector, from east counterclockwise.

In the south of the Pyrenees, the semi-diurnal tide amplitude presents a very clear north-south gradient with minimum tides in the north of the mountain range. The position of this minimum, displaced to the north of the mountain axis, would in fact contribute to the tide asymmetry observed from our measuring stations. Note that the stations in the north are closer to the mountain range that those in the south.

The diurnal amplitude shows a more complex pattern and greater spatial variability. In the south there is a clear maximum very close to Zaragoza, which extends to the south through the Ebro valley. A symmetrical maximum also exists in the north, but away from our observation domain. The amplitude is clearly modulated by the terrain elevation, with a strong decrease in the mountains, for which the amplitude is about ten times smaller than in the valley. There is a clear phase shift over the mountains, similar to but smaller than that observed by Chen, et al. (2001) over Taiwan.

Out of our measurement domain, both tides also seem to be affected by the relief of the Massif Central, in the northeastern corner of the domain represented in Figure 10.

Although the simulation period and the surface experimental data come from different years, the semidiurnal tide presents little interannual variation, so that both results can be compared. The comparison is made between synoptic stations and the closest grid point, both tides calculated for the summer period (JJA) and for the semi-diurnal tide. The result is shown in Figure 11. The model underestimates all semi-diurnal amplitudes, and this discrepancy is greater for continental stations (Carcassonne, Pau and Zaragoza). This can be explained by the relatively low upper model limit of $20 \mathrm{hPa}$, which will miss part of the ozone layer (Zwiers and Hamilton, 1986). As noted above, the north-south asymmetry is reproduced by the model. Both the simulated and experimental phases of the semi-diurnal tides are notably constant from one station to another, but there is a phase difference between experimental and model tides of about one hour.

In spite of the serious limitations pointed out, the results from the numerical model can capture some key features of the tidal distribution around the Pyrenees. Further research, with possible longer integration times and changes in the model parametrizations or the maximum height achieved by the simulation, is needed to refine these results and to obtain some clues about the causes of the distribution of the tide. 


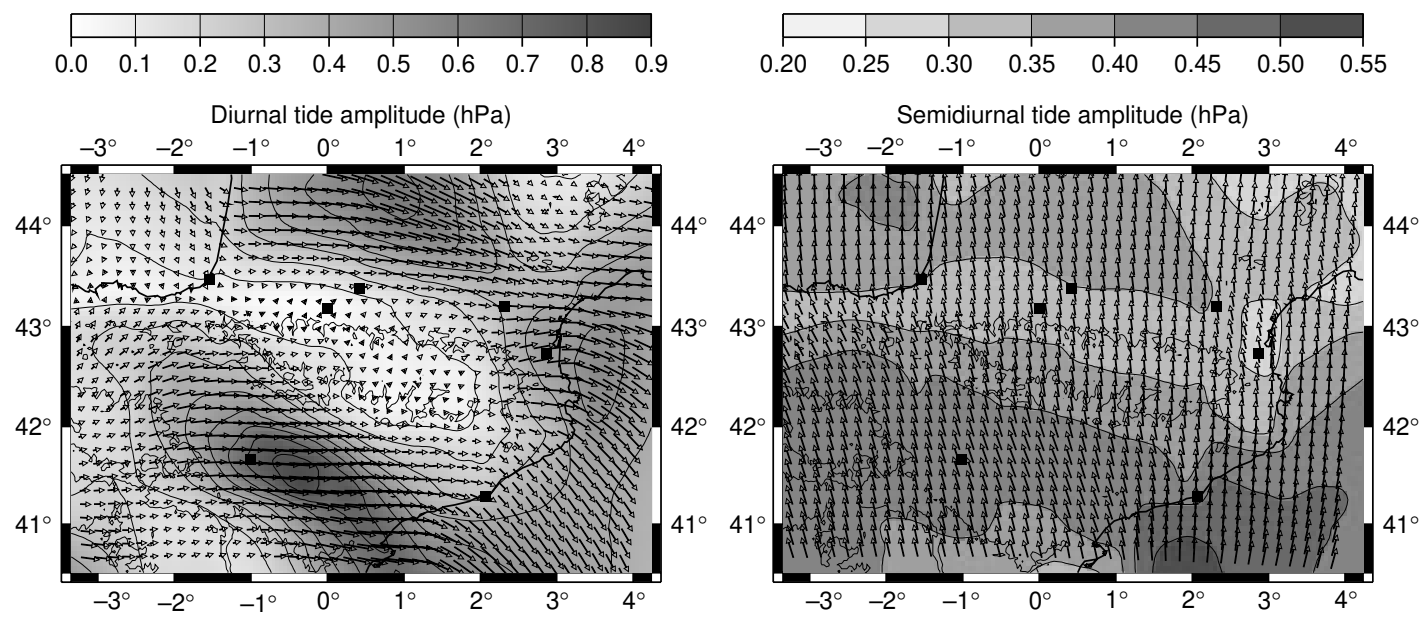

Figure 10. Amplitude and phase for the diurnal and semi-diurnal components of the pressure tide for the JJA period for the grid points of the simulation carried out. The vector's length is proportional to the amplitude and the phase is represented as the angle from the zonal eastwards direction, counterclockwise. Note that the amplitude scale is different between plots. The locations of synoptic stations are represented by squares.
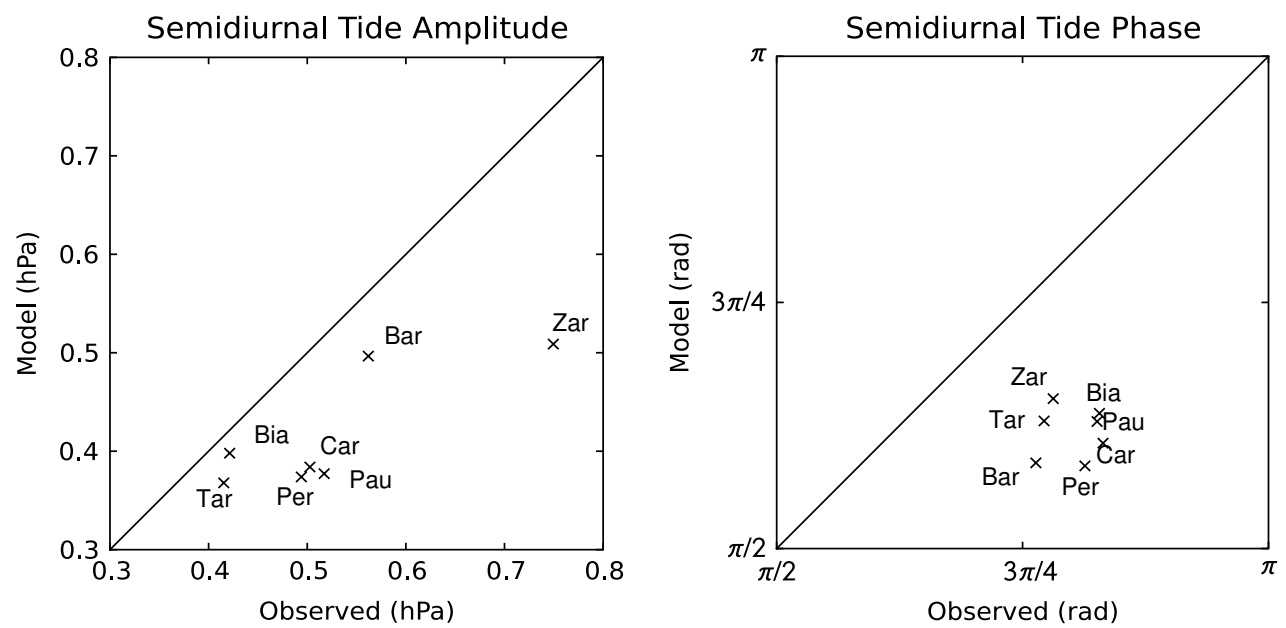

Figure 11. Comparison between the amplitudes and phases of semi-diurnal tides, as calculated from the synoptic station data and the nearest grid-point model simulation. The label for each point indicates the station.

\section{Conclusions}

Atmospheric tides around the Pyrenees mountain range have been analyzed using a one-year record of synoptic stations, two months worth of data from the PYREX database and a three-month long record from the Lannemezan VHF profiler. Clear semi-diurnal and diurnal signals have been obtained from all the data. Both geographical and seasonal variations are observed in the distribution of barometric tides around the mountains. There is a particularly strong variation in the diurnal component and a much weaker one in the semi-diurnal tide. Generally, the semidiurnal component is predominant, but a stronger diurnal amplitude, twice as great as the semi-diurnal tide amplitude, has been found in Zaragoza, the most continental station, in summer. A clear asymmetry is also found, especially in the semi-diurnal component of the tide, between the north and the south of the mountains. The semi-diurnal asymmetry is almost constant through the year, but the diurnal one presents a very intense seasonal cycle. This asymmetry in the semi-diurnal component has also been found in PYREX data.

The features observed in the tide cannot be explained by classical tide theory, which predicts only migrating, zonally constant planetary-scale tides and does not take into account any effects related to the terrain nature or topography. Several effects, summarized by Frei and Davies (1993), can be invoked to explain this variability in the tide. According to the above-cited authors, interference of the migrating wave tide with the topography is the main mechanism active in the Alps. From our observations, this can hardly be the only explanation in the case of the Pyrenees, because it does not explain the great seasonal variability observed. It could probably be applied, however, to explain the semi-diurnal tide asymmetry.

A three-month simulation using NCAR's WRF limitedarea model has been carried out to check the ability of the model to reproduce the tides, and in particular the spatial pattern and the asymmetry observed. The model results have been validated using the Lannemezan VHF wind-profiler record. The model reproduction of the wind is generally good above $4000 \mathrm{~m}$. The model is also able to reproduce the main features in the diurnal cycle of the wind, although the results are far from being quantitatively correct. The semi-diurnal barometric tide observed at the surface is in general well reproduced, and a north-south asymmetry is also obtained, although not as strong as in the observational data. There is a systematic bias in 
the phase. The diurnal tide is harder to compare, because the simulation and observational periods do not coincide and the temporal variability of this component makes any comparison uncertain. Nevertheless, a dipolar pattern is obtained, which leads to results qualitatively similar to those for the observed ground tides.

\section{Acknowledgements}

The authors are grateful for financial support by the ETORTEK Strategic Research Programme (Department of Industry, Trade and Tourism and Department of Transport and Civil Works of the Basque Government, Basque Meteorological Service-Euskalmet) through the EKLIMA21 project (ETORTEK IE08-217 and IE09-264). Funding was also received from the National $\mathrm{R}+\mathrm{D}+\mathrm{i}$ Plan, Spanish Ministry of Science and Innovation (CGL2008-03321/CLI).

The authors thank the ECMWF for granting access to reanalysis and operational data through the MARS archive system by means of the special project SPESIPRA. Comments by two anonymous reviewers have been very helpful and have led to a better final version of the paper.

\section{References}

Bartels J. 1927. Über die atmosphärischen Gezeiten. Abh. Preuss. Meteorol. Inst. 8.

Bartzokas A, Repapis CC, Metaxas DA. 1995. Temporal variations of atmospheric tides over Athens, Greece. Meteorol. Atmos. Phys. 55: $113-123$.

Bénech B, Koffi E, Druilhet A, Durand P, Bessemoulin P, Campins J, Jansá A, Terliuc B. 1998. Dynamics characteristics of regional flows around the Pyrénées in view of the PYREX experiment. Part I: Analysis of the pressure and wind fields and experimental assessment of the applicability of the linear theory. J. Appl. Meteorol. 37: 32-51.

Bessemoulin P, Bougeault P, Genovés A, Jansá A, Puech D. 1993. Mountain pressure drag during PYREX. Beitr. Phys. Atmos. 66: 305-325.

Bougeault P, Jansa Clar A, Bénech B, Carissimo B, Pelon J, Richard E. 1990. Momentum budget over the Pyrénées: The PYREX experiment. Bull. Am. Meteorol. Soc. 71: 806-818.

Chapman S, Lindzen RS. 1970. Atmospheric tides. Gordon and Breach Science Publishers, Inc.

Chen TC, Yen MC, Schubert S. 2001. Diurnal variation of pressureheights: A vertical phase shift. J. Climate 14: 3793-3797.

Cooper N. 1982. Inferring solar UV variability from the atmospheric tide. Nature 296: 131-132.

Cooper NS. 1984. Errors in atmospheric tidal determination from surface pressure observations. Q. J. R. Meteorol. Soc. 110: 1053-1059.

Dai A, Wang J. 1999. Diurnal and semi-diurnal tides in global surface pressure fields. J. Atmos. Sci. 56: 3874-3891.

Díaz de Argandoña J, Ezcurra A, Bénech B. 2003. Surface pressure disturbance in the Ebro Valley (Spain) produced by the Pyrenees mountains during PYREX. Q. J. R. Meteorol. Soc. 129: 1457-1468.
Frei CH, Davies HC. 1993. Anomaly in the Alpine diurnal pressure signal: observations and theory. Q. J. R. Meteorol. Soc. 119: 1269-1289.

Green JSA. 1970. The tidal motion of the atmosphere. Phys. Educ. 5: 37-40.

Hagan ME, Forbes JM. 2003. Migrating and nonmigrating semi-diurnal tides in the upper atmosphere excited by tropospheric latent heat release. J. Geophys. Res. 108: A2. DOI:10.1029/2002JA009466.

Hagan ME, Forbes JM, Vial F. 1995. On modelling migrating solar tides. Geophys. Res. Lett. 22: 893-896.

Hagan ME, Burrage MD, Forbes JM, Hackney J, Randel WJ, Zhang X. 1999. GSWM-98: Results for migrating solar tides. J. Geophys. Res. 104: $6813-6827$.

Hamilton K. 1980. The geographical distribution of the solar semidiurnal surface pressure oscillation. J. Geophys. Res. 85: 1945-1949.

Hamilton K, Ryan S, Ohfuchi W. 2008. Topographic effects on the solar semi-diurnal surface tide simulated in a very fine resolution general circulation model. J. Geophys. Res. 113: D17114.

Haurwitz B, Cowley AD. 1973. The diurnal and semi-diurnal barometric oscillations, global distribution and annual variation. Pure Appl. Geophys. 102: 193-222.

Hong SY, Dudhia J, Chen SH. 2004. A revised approach to ice microphysical processes for the bulk parameterization of clouds and precipitation. Mon. Weather Rev. 132: 103-120.

Hsu HH, Hoskins BJ. 1989. Tidal fluctuations as seen in ECMWF data. Q. J. R. Meteorol. Soc. 115: 247-264.

Kato S. 1981. Atmospheric tides - a review. J. Atmos. Terr. Phys. 43 $491-493$.

Lindzen RS. 1979. Atmospheric tides. Ann. Rev. Earth Planet. Sci. 7: 199-225.

Mass CF, Steenburgh WJ, Schultz DM. 1991. Diurnal surface-pressure variations over the continental United States and the influence of sea level reduction. Mon. Weather Rev. 119: 2814-2830.

Mori Y. 1984. Semidiurnal tidal oscillation at Marcus island. Mon. Weather Rev. 112: 755-760.

Ray RD. 2001. Comparisons of global analyses and station observations of the $s_{2}$ barometric tide. J. Atmos. Solar-Terr. Phys. 63: 1085-1097.

Ray RD, Ponte RM. 2003. Barometric tides from ECMWF operational analyses. Ann. Geophys. 21: 1897-1910.

Riggin DM, Kudeki E, Feng Z, Sarango F, Lieberman RS. 2002. Jicamarca radar observations of the diurnal and semi-diurnal tide in the troposphere and lower stratosphere. J. Geophys. Res. 107:.

Skamarock WC, Klemp JB, Dudhia DOG, Barker DM, Wang W, Powers JG. 2007. 'A description of the advance research WRF Version 2', Technical Note NCAR/TN-468+STR. NCAR: Boulder, Colorado.

Smith RB. 1979. The influence of mountains on the atmosphere. $A d v$ Geophys. 21: 87-230.

van den Dool HM, Saha S, Schemm J, Huang J. 1997. A temporal interpolation method to obtain hourly atmospheric surface pressure tides in reanalysis 1979-1995. J. Geophys. Res. 102: 22013-22023.

Willson MAG. 1975. Atmospheric tidal motions over Australia below 20 kilometers. Mon. Weather Rev. 103: 1110-1120.

Zwiers F, Hamilton K. 1986. Simulation of solar tides in the Canadian Climate Centre general circulation model. J. Geophys. Res. 91: $11877-11896$ 